\title{
A herança da filosofia dos primeiros românticos na problematização da tese do fim da arte de Arthur Danto
}

The legacy of the early romantic philosophy in questioning the thesis of the end of art by Arthur Danto

Antônio Carlos Vargas Sant'Anna ${ }^{1}$ 


\section{Resumo}

$\mathrm{O}$ artigo analisa as consequências de se considerar a tese da diluição das fronteiras entre arte e filosofia, elaborada pelos primeiros românticos de Jena, na proposição do fim da arte de Arthur Danto. Busca evidenciar que o motivo pelo qual o autor de O Descredenciamento Filosófico $D a$ Arte desconsidera a tese românti$\mathrm{ca}$, se encontra na divergência ontológica entre esta e a visão hegeliana na solução do problema do limite do conhecimento imposto por Kant. Ao mesmo tempo, levanta a possibilidade de se compreender o processo que leva ao fim da arte não apenas como resultado de um processo dialético entre a arte e a filosofia da arte, mas também como resultado de uma relação dialógica entre duas vertentes herdeiras das proposições românticas.

Palavras-chave: Arthur Danto; Românticos de Jena; fim da arte

\section{Abstract}

This paper analyzes the consequences of considering the thesis of the blurring of the limits between art and philosophy, elaborated by Jena's early romantics, in Arthur Danto's proposition of the end of art. It searches for showing that the reasons the author of The Philosophical Disenfranchisement of Art has had for disregarding the romantic theory was the ontological difference between it and the Hegelian's view about the solution of the problem of the boundaries of knowledge imposed by Kant. At the same time, it raises the possibility for understanding the process which leads to the end of art not only as a result of a dialectical process between art the philosophy of art, but also as a result of a dialogic relationship between two aspects that are inherited from the romantic propositions.

Keywords: Arthur Danto; Jena's romantics; end of art
ISSN: 1414.5731

E-ISSN: 2358.6958

1 Professor Dr. Associado da Universidade do Estado de Santa Catarina (UDESC), atuando junto ao PPGAV. 
De todos os movimentos culturais surgidos no ocidente, sem dúvida, o Romantismo é o que maior impacto ainda tem sobre a concepção artística vigente.

O que podemos dizer que devemos ao Romantismo? Muita coisa. Devemos ao Romantismo a noção de liberdade do artista e o fato de que nem ele, nem os seres humanos em geral podem ser explicados por noções simplistas, como as que predominavam no século XVIII e como ainda são enunciadas por analistas excessivamente racionais e científicos, seja em relação aos seres humanos ou aos grupos. Também devemos ao Romantismo a ideia de que uma resposta unificada quanto aos assuntos humanos provavelmente será ruinosa; que, se você realmente acredita que há uma única solução para todos os males humanos e que você deve impor esta solução a qualquer custo, você provavelmente se tornará um tirano violento e despótico em nome de sua solução, pois seu desejo de remover todos os obstáculos a ela vai acabar destruindo as criaturas que você pretende beneficiar ao oferecer a solução. A visão de que há muitos valores e que eles são incompatíveis; toda a noção de pluralidade, de inesgotabilidade, da imperfeição de todas as respostas e arranjos humanos; a ideia de que nenhuma resposta que afirme ser verdadeira, seja na arte ou na vida, pode, em princípio, ser perfeita ou verdadeira - tudo isso devemos aos românticos (Berlin, 2015, p. 216).

Acreditamos que esta citação de Berlin, é não apenas a mais adequada para abrir um artigo que se proponha problematizar a tese do fim da arte, elaborada por Arthur Danto, como é, possivelmente, a mais adequada para fechá-lo.

Agora, se devemos tanto ao romantismo, porque este não aparece na análise de Danto?

Uma das primeiras questões que se deve ter em mente é que a definição do termo Romantismo, ou romântico, não é simples pela pluralidade e amplitude do movimento que, muito mais que um movimento artístico na acepção formal do termo, é mais bem uma concepção filosófica de mundo no qual a arte ocupa um papel fundamental.

Essa grande amplitude do romantismo evidencia dois fatores que dificultam defini-lo. Primeiro, os românticos, em geral, buscaram mais borrar demarcações do que desenhá-las, apagar fronteiras do que fixá-las, misturar gêneros do que conceituá-los. Segundo, seu caráter transgressor os fazia atacar cada fundamento conquistado e cada caracterização mais sólida, que eram rapidamente derrubados pelo poder corrosivo de sua própria crítica. [...] Definir o romantismo seria impossível, por conta das diversas matrizes envolvidas nesse fenômeno cultural que se desenrolou entre 1780 e 1848 no Ocidente. Para além das divergências nacionais e das diferenças ideológicas, até essa suposta limitação cronológica pareceria extremamente flexível. Resumindo, a dificuldade de compreender o romantismo não advém da escassez de definições sobre ele, e sim do excesso" (Duarte, 2011, pp. 11,12).

No início de sua obra, Após o fim da Arte, Arthur Danto ao comentar a visão de História da Arte de Greemberg, destaca que o ao contrário da pintura maneirista que sucede a renascentista, do rococó que sucede o barroco e é sucedido pelo neoclássico e este pela pintura romântica, o modernismo não seguiria esta linha sucessória pelo nível diferenciado de consciência que a pintura refletiria. Nas palavras do autor:

Minha percepção é a de que o modernismo não segue o romantismo dessa maneira, ou não meramente: ele é marcado por uma ascensão a um novo nível de consciência, que se reflete na pintura como um tipo de descontinuidade, quase como se enfatizasse que a representação mimética se tornou menos importante 
do que algum tipo de reflexão sobre os meios e métodos de representação (Danto, 2016, p.10).

Neste artigo busca-se relativizar a tese de Artur Danto sobre o fim da arte, chamando atenção para a existência de uma ressonância de ideias oriundas do primeiro romantismo (grupo de Jena) no Século XX. Não se trata, portanto, de um argumento de negação para com a tese do filósofo americano - a qual consideramos brilhante - e sim, de evidenciar que, incluir a herança romântica no escopo da tese a problematiza², pois, a produção artística identificada por Danto como aquela que demonstra a autoconsciência da arte passa a ser vista como consequência de um processo que também foi possível pelas proposições filosóficas românticas de diluição das fronteiras entre filosofia e arte. Este novo nível de consciência que Danto identifica no modernismo não seria apenas fruto de um processo histórico prenunciado pela tese hegeliana e sim, também, consequência de um processo histórico no qual a filosofia romântica da arte desempenhou um papel significativo não devendo, portanto, ser excluída.

A tese de Danto, marcadamente hegeliana, entende o fim da arte quando esta encontra seu fundamento ontológico desmarcando-se da filosofia da arte, assumindo ela própria sua filosofia ou, tornando-se neste sentido, filosofia de si própria (Danto, 2014, p.120) Assim, a arte chega ao seu fim num sentido desenvolvimentista porque, esta autodefinição uma vez encontrada liberta a arte do peso da história e da filosofia permitindo que os artistas ficassem "livres para fazer arte da maneira que desejassem, para quaisquer finalidades ou mesmo sem finalidade nenhuma" (Danto, 2006, p.18). Ou como diz em O descredenciamento filosófico da arte:

Pode haver desenvolvimento da arte depois do fim da arte, mas nenhum desenvolvimento essencial, isto é, não mais progresso na procura da arte por autodefinição adequada (Danto, 2104 P.16).

No entendimento de Danto, a arte e a filosofia da arte possuem uma relação histórica, cujo marco inicial pode ser localizado na teoria platônica que vê a arte como perigosa e assim a coloca num espaço idealista que anula o seu potencial revolucionário ou de ação na vida social. "Foi mais ou menos por estas razões que diagnostiquei a teoria platônica da arte como amplamente política, um movimento numa luta pela dominação sobre a mente dos homens, na qual a arte é concebida como o inimigo" (Danto, 2014, p.40).

É esta visão da filosofia, a qual descredencia filosoficamente a arte a que marcaria o desenvolvimento da arte, mas que seria superada, pela própria arte, quando esta ao assumir num processo histórico sua própria autoconsciência chega ao fim deste processo. A partir deste fim, esta filosofia da arte perde sua importância e sentido histórico como discurso válido para pensar a arte.

Já a História da arte, enquanto disciplina narrativa construída a partir de uma visão desenvolvimentista da perspectiva, ou seja, da capacidade de representação da experiência perceptiva, é descredenciada pelas modificações modernistas que, segundo Danto, são causadas na arte pelo surgimento do cinema (Danto, 2014, p.156) uma vez que este abre as portas para a superação da filosofia da arte pela própria

2 No sentido foucaultiano do termo. 
arte. Como consequência deste processo histórico quando a arte chega ao fim a História da Arte enquanto disciplina também chega a seu fim (Danto, 2014, p.137)

Filosofia da arte e história da arte estabelecem assim uma relação dialética que permite visualizar o fim da arte, pois, esta somente pode ser percebida pelo fim da história da arte como narrativa da trajetória desenvolvimentista da representação mimética, no entanto, o que demarca a evidência do fim da arte como processo historiográfico somente pode ser percebido na relação desta com o a filosofia da arte. Arte, Filosofia da arte e História da arte formam um triangulo no qual a arte ocupa sempre o papel de síntese.

$\mathrm{Na}$ visão de Danto, a produção artística que encontra sua condição filosófica é a produção marcada a partir de uma tradição Duchampiana que culmina no aparecimento da Pop Art. Esta condição filosófica estaria demonstrada no instante em que a arte - definida pela Filosofia da arte e pela História da arte enquanto objeto que representa - não mais pode ser diferenciada do (objeto) que representa. Sejam por seus vínculos com a representação ou com vivências ritualísticas (pré-lógicas) ficam assim anacrônicos os aparecimentos de outras manifestações artísticas contemporâneas, como o neoexpressionismo dos anos 1980 (Danto, 2014, p.29) ou algumas performances (Danto, 2014, p.170), já que estas manifestações habitariam um tempo pós-histórico.

\footnotetext{
Obviamente haverá ainda a feitura de arte, mas os fazedores de arte, vivendo no que gosto de chamar período "pós histórico" da arte, trarão à existência obras que carecem da importância ou do significado históricos que esperamos delas desde muito tempo. O estágio histórico da arte se conclui quando sabemos o que é a arte e o que ela significa. Os artistas deixaram o caminho aberto para a filosofia, e chegou o momento de finalmente transferir a tarefa para a mão dos filósofos (Danto, 2014, p.148).
}

A arte contemporânea, desta forma, pode ser entendida não como pertencente a um período histórico, mas por um modo de ser, ou nas palavras do autor por ser "uma arte produzida dentro de certa estrutura de produção jamais vista em toda a história da arte" (Danto, 2006, p.12).

O primeiro ponto que se deve ter em consideração para pensar o papel da filosofia da arte romântica (e sua herança) numa problematização da tese de Danto é o fato que a filosofia da arte platônica - ponto de partida da histórica relação entre filosofia e arte adotada por Danto - é basicamente formulada para resolução do conflito entre filosofia e poesia, e não entre filosofia e artes plásticas (pintura e escultura) que ocupam um papel secundário (Vares, 2010). E não toda e qualquer poesia, mas especificamente, entre a nascente filosofia e a Tradição Homérica. (Pinheiro, 2007) e (Villela-Peti, 2003). A relação sócio histórica entre Platão e os Poetas está emoldurada pelo papel que o autor de $A$ República buscava para a filosofia no âmbito da educação ateniense que era feita, ainda em sua época, de forma preponderante pelos poetas de Tradição homérica.

A bem dizer, ao falar de poesia, Platão não está se referindo a tudo aquilo que se apresenta como poema. "Poesia" no contexto da República tem a ver com as composições dos grandes poetas da tradição, e, sobretudo, com a poesia mimética, seja ela épica ou trágica. Antecipa-se de certo modo aqui o que será explicitamente enunciado na Poética de Aristóteles, isto é, que nem tudo o que é exposto em verso deve ser considerado como poesia. $\mathrm{O}$ fato de escrever em versos não basta para definir o "poeta" (Villela-Petit, 2003, p.52). 
Este, era o real marco social de um conflito pelo predomínio sobre a educação ateniense, uma vez que na visão platônica, a poesia homérica atribuiria aos deuses um comportamento que era espelhado no comportamento humano. Sob este ponto de vista, não apenas este comportamento não refletiria o comportamento original (puro, da teoria das ideias) como não seria educativo já que tomava como modelo um comportamento impuro e desvirtuado, carente dos verdadeiros valores morais que apenas a ação da filosofia poderia revelar. A crítica à mímesis, no sentido platônico, não é generalizada, mas objetivamente direcionada a este tipo de ação mimética que se serve de modelos corrompidos:

Isso, porém, não quer dizer que toda mímesis, toda imitação, seja por si própria condenada. É preciso conservar para os jovens a possibilidade de imitar aqueles heróis que se distinguem pela beleza de seu caráter e de sua conduta. Esboça-se a distinção que se delineará mais claramente nos diálogos ulteriores e, em particular no Sofista, entre uma boa mímesis e uma má mímesis, embora o traço dominante da República, em contraste com o Fedro, o Banquete e o Sofista, seja ainda uma grande desconfiança em relação à poesia e à arte mimética. [...] No Livro VI temos uma comparação magnífica entre o pintor e o filósofo, pois aí, em 500E, o filósofo é dito ser como um pintor fazendo sua obra com os olhos voltados para um modelo divino. Esta comparação vem logo depois de uma interpelação de Sócrates a Adimanto: "Acredita você que, quando se vive com aquilo que se admira, seja possível não imitá-lo? ". O verbo mimeîsthai, 'imitar', é aqui empregado de maneira totalmente positiva (Villela-Petit, 2003, p.65,67).

Sob esta ótica, o cerne da polêmica platônica estaria na questão educacional que evidentemente é o cerne do tema da República. Este papel educacional não era associado às artes plásticas da época, pois, embora a pintura e a escultura pudesse contribuir para a educação, os pintores e escultores não eram encarregados da educação das castas (cidadãos) atenienses, mas apenas os poetas e os filósofos.

Para apreciarmos a posição de Platão, é bom nos tornarmos mais atentos, graças à experiência dos antropólogos, ao que representa a palavra dos poetas dentro de uma sociedade onde prevalece a tradição oral. Não se constitui ela como a referência imprescindível enquanto depositária dos valores e ensinamentos éticos? A palavra dos poetas tinha então tudo a ver com a paideía, isto é, com a educação em sentido lato e, portanto, com a formação do êthos. Os poetas eram verdadeiramente os mestres, os educadores da Grécia, como se dizia sobretudo de Homero (Villela-Petit, 2003, p. 55).

Tal fato não impediu que as relações entre filosofia e arte na doutrina platônica influenciassem a produção de imagens, como Danto bem evidencia ao demonstrar o inequívoco vínculo histórico entre filosofia e artes plásticas no processo que conduz ao fim desta última tal como aquela a compreendia. Mas esta relação entre filosofia e poesia é importante no argumento que aqui apresentamos porque tal como no pensamento platônico é o núcleo da filosofia dos primeiros românticos, fato que tampouco impediu - muito pelo contrário - sua posterior influência na definição da arte e na produção de imagens.

Tendo escrito antes de Hegel, os primeiros românticos alemães concordariam com ele, em parte [grifo meu], quanto ao contato da arte com o sensível, que não o copia, mas o enforma. Só que essa operação é diferente para eles, pois não 
busca salvar as coisas sensíveis de sua pobre materialidade, já que esta não seria assim tão pobre. Todos os produtos da arte são, para os românticos, poemas escritos sobre a poesia primeira, que já é a do mundo (Duarte, 2011, p.158).

O segundo ponto a se ter em consideração sobre a problematização que a herança romântica traz a tese de Danto, portanto, está dado pelas diferenças filosóficas entre Hegel e os primeiros românticos - seus contemporâneos - uma vez que Danto adota abertamente a visão hegeliana mas este, junto a Fichte e Schelling encontram-se ligados pelo mesmo interesse ontológico no qual a subjetividade desempenha um papel central e que, define, o idealismo pós-kantiano (Markus \& Zizek, 2012). Se as divergências filosóficas entre Hegel e Schelling, estão evidenciadas nas recorrentes referências de um a outro a postura crítica de Hegel para com o solipsismo da arte romântica é bastante clara ${ }^{3}$.

[...] en el arte romántico el modo de configuración efectivamente real no va por tanto más allá, por el lado de la manifestación externa, de la realidad efectiva ordinaria propiamente dicha, y de ningún modo vacila en asumir en sí este ser-ahí real en su infinita deficiencia y determinidad. Aquí ha desaparecido por tanto aquella belleza ideal que eleva a la intuición inmediata por encima de la temporalidad y las huellas de la caducidad, para poner la floreciente belleza de la existencia en el lugar de su de otro modo marchitada apariencia. El arte romántico ya no tiene como meta la libre vitalidad del ser-ahí en su infinita quietud y abismamiento del alma en lo corpóreo, ni esta vida como tal en su concepto propio, sino que vuelve la espalda a este colmo de la belleza; entrelaza lo interno suyo también con la contingencia de la formación externa y concede un margen sin reservas a los marcados rasgos de lo feo. [...] Lo interno de esa relación, llevado hasta el extremo, es la exteriorización carente de exterioridad, que, por así decir invisiblemente, solo se percibe a si misma, un sonar como tal, sin objetualidad ni figura, un flotar sobre las aguas, un resonar sobre un mundo que dentro y en sus heterogéneos fenómenos solo puede asumir y reflejar este ser-en-si del alma (Hegel, 1989, p.388). ${ }^{4}$

\footnotetext{
3 É preciso, como recorda Hernandez Javier, destacar que as críticas de Hegel a arte romântica estão direcionadas sobremaneira a produção pictórica nazarena. Com relação a valorização da arte por sua função na cultura, Hegel e o Romantismo são aliados; quanto ao alcance na satisfação desta eles polemizam. Mas seria injusto fazer do Romantismo e da filosofia do idealismo blocos compactos. Não só são porosos um para o outro, senão que cada frente abriga em si mesma diferenças internas extremas. Para o debate sobre religião da arte ou compreensão da arte, as polarizações vão se acentuando por uma das artes em particular, pela arte da pintura. Portanto, não entram em jogo a enorme contribuição à literatura e sua teoria em cujo âmbito o romantismo mantém tanta atualidade, nem entra em jogo essa típica destinação romântica da arte à revolução permanente, que nem mesmo a crise das vanguardas da metade do século XX conseguiu extinguir. Tampouco é toda a pintura que acende o debate entre Hegel e o romantismo, e sim essa direção politicamente tendenciosa, ideologicamente justificada e institucionalmente promovida e protegida que sob o título de " pintura neo-alemã patriótica e cristã " foi defendida por Friedrich Schlegel, para proteger os "Nazarenos"(Hernandez, 2003, p.173).

Con relación a la valoración del arte por su función en la cultura, Hegel y el Romanticismo son aliados; en cuanto al alcance en la satisfacción de dicha función, en ello polemizan. Pero sería injusto hacer del Romanticismo y de la filosofía del Idealismo bloques compactos. No sólo son porosos uno para el otro, sino que cada frente cobija en sí mismo diferencias internas extremas. Para el debate sobre religión del arte o comprensión del arte, las polarizaciones se van acentuando por una de las artes en particular, por el arte de la pintura. No entra por lo tanto en juego la enorme contribución sobre la literatura y su teoría, en cuyo ámbito el Romanticismo mantiene tanta actualidad, ni entra en juego esa típica destinación romántica del arte a la revolución permanente, que ni siquiera la crisis de las vanguardias del mediados del siglo XX ha hecho extinguir. Y tampoco es toda la pintura la que enciende el debate entre Hegel y el Romanticismo, sino esa dirección políticamente sesgada, ideológicamente justificada e institucionalmente promovida y amparada, que bajo el rótulo de "pintura neoalemana patriótica y cristiana" fue defendida por Friedrich Schlegel, para proteger a los "Nazarenos"). (Tradução nossa.)

4 [...] na arte românica o modo de configuração efetivamente real não vai portanto mais longe, pelo lado da manifestação externa de uma realidade ordinária propriamente dita, e de nenhuma maneira hesita em assumir este ser-aí real em sua infinita deficiência e determinidade. Aqui desapareceu, portanto, aquela beleza ideal que eleva a intuição imediata acima da temporalidade e as marcas de sua caducidade, para colocar a florescente beleza da existência no lugar de sua de outro modo envelhecida aparência. A arte romântica não tem o objetivo a livre vitalidade do ser-aí em seu infinito silêncio e abismo da alma no corpóreo, nem esta vida como tal em seu conceito próprio senão que vira as costas a este máximo de beleza; entrelaça o interno seu também com a contingência da formação externa e concede uma margem sem reservas aos marcados traços do feio. [...] 0 interior desta relação levado ao extremo, é a exteriorização desprovida de exterioridade, que, por assim dizer invisivelmente só se percebe a si mesma, um soar como tal, sem objeto nem figura, um flutuar sobre as águas, um ressoar sobre um mundo que dentro e em seus heterogêneos fenômenos só pode assumir e refletir este ser-em-sí da alma. (Tradução nossa).
} 
Para o tema que aqui nos atém, interessa menos o detalhamento dos argumentos filosóficos que Hegel e os primeiros românticos - especialmente Schelling desenvolvem para sustentar suas teses idealistas do que o como cada um soluciona o problema. E o problema estava dado pela limitação do conhecimento que impôs Kant ao determinar que este é passível apenas aos fenômenos, mas inacessível a essência dos mesmos, isto é, ao númeno (o em si).

$\mathrm{Na}$ visão hegeliana, expressa pela sua lógica da reflexão, o númeno é apenas um efeito colateral do movimento de absoluta negatividade uma vez que "a substância do sujeito é posta apenas retroativamente pelo processo de autoconstituição do sujeito" (Gabriel, 2012, p.71). A subjetividade assim, ontologicamente, coloca-se a si mesma, criando um campo de sentido num mundo que precisa ser habitado e, portanto, é passível de compreensão por um processo reflexivo do qual a dialética hegeliana se propõe de dar conta. Para Hegel, a fenomenização do numênico é inevitável.

[...] Hegel define a distinção entre a essência ser algo determinado e a determinidade da essência. A ideia por trás dessa distinção é que não se deveria referir à essência no modo objetivo: não é algo determinado que existe lá fora, digamos assim. A essência não existe como uma entidade dentre outras, oferecendo-se a reflexão. Uma tal visão da essência (do em sí) acarretaria um retrocesso para a esfera do ser. $\mathrm{O}$ em sí não existe independentemente de nossa atividade de conceitua-lo (Gabriel, 2012, p. 73).

Schelling, por outro lado, vê a reflexão como parte de um domínio maior, acessível somente do âmbito da mito-poiesis. Para ele, negando as abordagens que enxergam o mito como uma narrativa que se refere à outra coisa que não a um sentido fundador (alegoria num sentido semiótico), o mito comparece como uma linguagem anterior à linguagem racional, portanto pré-lógica, e assim fundador do todo e qualquer marco conceitual que possa ser utilizado na conceptualização do conhecimento pois toda e qualquer linguagem racional estaria fundada numa linguagem anterior (pré-lógica). Como afirma Markus Gabriel "Quaisquer que sejam as possibilidades de uma leitura de Hegel como filosofia da finitude e da contingência, fica óbvio que, em última instância, Hegel se revela um otimista no que diz respeito aos recursos de sua dialética" (Gabriel, 2012, p. 92) Para Schelling, os mitos encarnam a própria unidade de sentido do ser, uma unidade que é de forma e conteúdo e que se rebela a uma dominação do Logos. De fato, para Schelling, a reflexão é que é limitada pela mitologia e não o contrário. Esta é base conceitual-filosófica sob a qual os primeiros românticos irão propor a necessidade do surgimento de uma nova mitologia que seja capaz de unificar filosofia e poesia (arte). Segundo Gabriel (pp:93) Hegel acredita erroneamente que o ser em Hölderlin e Schelling designa uma entidade anterior a reflexão mas para este, ao contrário, o ser define a união de forma e conteúdo que somente se tornam transparentes, por exemplo, na experiência estética (Hölderlin) ou na consciência mitológica (Schelling). Pois, como afirma Pedro Duarte:

Não caberia à arte, portanto, socorrer este mundo, como queria Hegel. Nem, contudo, restaria a ela apenas copia-lo, como acusara Platão. É outra a posição romântica. Para ela, o papel da arte seria o de fazer este mundo ressurgir como forma e consciência, adentrando a cultura do homem em sua relação com o que o cerca. ' É essencialmente próprio a toda a arte associar-se ao cultivado' afir- 
mou Schlegel. Já que somos parte da natureza e ela mesma é criadora, também fazemos, ou seja, criamos e produzimos poemas e os lemos - cultivamos. Somos seres poéticos, da poiésis, Modelo e cópia deixaram de ser o par explicativo do contato entre verdade e arte. [Grifo nosso] Esta faz parte do próprio movimento pelo qual a verdade cumpre seu ciclo de vida como criação, natural e humana (Duarte, 2011, p.158-159).

Os românticos, de fato, foram os primeiros, não em enxergar o conflito entre a filosofia e a arte, mas sim em propor uma solução definitiva ao problema; a sua unificação. Assim como a filosofia deveria se tornar poética (arte), resgatando a experiência primeira da vivência do mito (para superar os limites do conhecimento imposto pelo marco conceitual da linguagem lógica), a arte deveria transformar-se em filosofia assumindo sua natureza reflexiva.

Poesía y filosofía son un todo indivisible, eternamente vinculadas, aunque rara vez juntas, igual que Cástor y Pólux. Entre ambas se reparten el supremo territorio de cuánto hay de grande y sublime en la humanidad. Mas en el punto central se encuentran sus dos distintas direcciones: aquí en lo más íntimo y más sagrado, el espíritu está todo entero y poesía y filosofía son por completo una misma cosa y se hallan fundidas (Schegel, 1994, p.83). ${ }^{5}$

E é esta proposição romântica de resgate da unidade entre arte e filosofia, a qual consideramos que, se incorporada a tese de Danto a problematiza, pois, a fundamentação que dilui as fronteiras entre arte e a filosofia da arte que a descredencia, está na base da formulação filosófica romântica e não na proposição hegeliana.

Sendo assim, as condições históricas que permitiram o surgimento de uma autoconsciência da arte - e consequentemente seu fim (histórico) - são devedoras de uma herança romântica que Danto, ao seguir a tese hegeliana, não poderia aceitar pois implicaria no reconhecimento de um aporte filosófico contrário. Isto fica evidente pelo fato que, em grande medida, o modernismo é, também, influenciado pela herança romântica, fato que Danto tampouco reconhece.

A influência romântica durante o Século XIX e XX, é historicamente reconhecível em Van Gogh, Munch, Holder, Nolde, Marc, Kandisnky, Klee, Ernst e Mondrian e chega ao expressionismo abstrato, como bem evidencia o magnífico estudo de Robert Rosemblum (1993) A pintura moderna e a tradição do Romantismo nórdico. Isto não significa que a tese de Danto está equivocada. Significa, que duas linhas atravessam o modernismo. Uma, é fundada nas proposições teóricas que defendiam a superação das dicotomias entre arte e filosofia e que permitiu o surgimento de uma produção artística capaz de superar as diferenças entre arte como representação (do fenômeno) e arte como essência (numeno), tornando-se assim, a arte, a representação do que ela é (em si) pela impossibilidade de uma diferenciação do que ela representa. É esta produção - da qual Duchamp é fundador e, a Art Pop através da obra Brillo Box de Warhol, é a conclusão que é identificada por Danto como a arte que chega ao seu final. No entanto não se deve esquecer que antes das proposições que no início do Século XX defenderam a superação das fronteiras conceituais entre arte e filosofia, se encontram as teses românticas.

5 Poesia e filosofia são um todo indivisível, eternamente ligadas, embora raramente juntos, como Cástor e Pólux. Entre ambas se divide o supremo território do quanto existe de grande e sublime na humanidade. Mas no ponto central se encontram suas duas distintas direções: aqui no mais íntimo e mais sagrado, o espírito está todo inteiro e poesia e filosofia são por completo uma mesma coisa e se encontram fundidas. (Tradução nossa). 
Uma outra linha, no entanto, em cuja repercussão das teses românticas foi maior deu origem a toda uma produção que (como mostra Rosemblum), herdeira de parte das formulações do conceito de gênio, não rompem completamente com a tradição da representação - ao menos no âmbito da pintura - uma vez que, ao não romper plenamente com seus elementos físicos constitutivos (tela, tinta, linha, cor, forma, etc.) seguiu se apresentando como tal, isto é, como pintura. É esta linha que sem ruptura se vincula a toda uma gama de obras contemporâneas (transvanguarda, neoexpressionismo, etc.) que Danto identifica como anacrônicas por surgirem num período temporal "pós-histórico".

É possível, no entanto, pensar a relação entre estas duas linhas como a de uma relação dialógica que se desenvolveu ao longo dos séculos XIX e XX e que ocorreu concomitantemente com uma relação dialética entre arte e filosofia da arte. Se isto é viável, a síntese dialética formulada pela arte que chega a sua consciência também incluiria elementos presentes da linha que continua a tradição representacional e vice-versa. Uma evidência disso é Mondrian. Enquanto Rosemblum afirma:

[...] fue el holandés Piet Mondrian quien aportó el eslabón más claro y más interesante artísticamente entre una tradición decimonónica basada en los temas, espacios y emociones del arte romántico nórdico y la transformación de esas raíces históricas en un arte de este siglo donde ha quedado suprimida toda referencia explícita al mundo material (Rosemblum, 1993, p. 199 - 200). ${ }^{6}$

Rosalind Krauss por outro lado, sobre o mesmo Mondrian diz que: "No hay manera de penetrar en su arte sin asimilar el absoluto grado de abstracción de la lógica de Hegel" (Krauss, 1996, p. 254). ${ }^{7}$

Muitas das produções artísticas que podem ser associadas (ou possuem vínculos) com a arte que atinge seu fim - como as performances dos anos 60 e 70 - possuem características que se pode relacionar com a herança romântica sem que necessariamente sejam anacrônicas (embora algumas sejam se seguimos stricto sensu a tese de Danto).

Das diversas características necessárias à arte definidas pelos primeiros românticos e que constituem a linha representacional duas atravessaram o modernismo chegando através deste processo dialógico à arte contemporânea: a relação entre arte e revolução e a valorização da subjetividade.

A relação entre arte e revolução teve origem na influência do ideário da revolução francesa sobre os primeiros românticos e se manteve impulsionada pela situação de instabilidade política que perdurou na Europa durante praticamente todo o Século XIX (com períodos de grande intensidade revolucionária, como os de 1820, 1830 e especialmente as de 1848 coincidentemente ano do lançamento do Manifesto comunista de Marx) que adentrou o século XX ganhando um novo e forte impulso com a revolução russa de 1917. Mas a identificação dos primeiros românticos não foi absoluta, pois, se liberdade e fraternidade iam ao encontro das teses românticas o mesmo

6 Foi o holandês Piet Mondrian quem forneceu o elo mais claro e interessante artisticamente entre a tradição artística do século XIX, com base nos temas, espaços e emoções da arte romântica nórdica e transformação dessas raízes históricas na arte deste século onde ficou suprimida toda a referência explicita ao mundo material. (Tradução nossa)

7 Não existe maneira de penetrar na sua arte sem assimilar o absoluto grau de abstração da lógica de Hegel. (Tradução nossa) 
não ocorria com a igualdade já que estes defendiam a diferença, fato evidenciado nas críticas ao racionalismo iluminista. O modernismo, como um todo, estimulou a tese romântica da liberdade no artista como criador de novas regras e esta herança se manteve nas produções que valorizaram a crítica política e das superestruturas ideológicas estando presente em muitas manifestações da performance bem como na temática de outras linguagens artísticas que passaram a adotar a crítica política ou cultural como instrumento de afirmação.

Esta herança que associa o fazer artístico com o comportamento questionador/revolucionário permanece na arte contemporânea tanto através das práticas que tomam o excluído social como objeto temático, como é exemplo toda produção artístico-contemporânea fotográfica de caráter antropológica, de artistas como Lothar Baumgarten, Chistian Boltanski, Rimer Cardillo, Carlos Capelán, Mark Dion e as obras dos brasileiros Claudio Edinger, Alice Miceli, Oiticica, Armando Queiroz, Caetano Dias ou Paulo Nazareth, assim como naquelas que questionam o sistema político ou de validação e institucionalização artístico de museus e galerias, das quais os exemplos mais paradigmáticos são oriundos das práticas performáticas dos anos sessenta e setenta surgidas em espaços alternativos como Roup Material, Guerrillha Girls, Grand Fury, Colab, PADD ou ADC do Rio entre outros e mais recentemente das práticas de arte ativista como um todo.

Se pensarmos na produção de vertente conceitual, a herança destas características constituintes do gênio artístico/romântico parece descabida, mas se olharmos para toda uma tradição já estabelecida da performance como por exemplo, de Beuys, de Abramovich, de Mendieta, do teatro espanhol da La Fura Dels Baus, ou do brasileiro Teatro da Vertigem bem como em grupos herdeiros de Grotowski (cuja influência do poeta romântico Adam Mickiewicz foi por ele próprio assumida publicamente), da dança numa tradição oriunda dos trabalhos de Pina Bausch, vemos que a herança romântica da negação das regras ( dos valores da cultura ocidental) e da valorização do natural (da espontaneidade e do instintivo) ainda perdura na produção artística contemporânea.

No que se refere a subjetividade como uma característica positiva fundamental da filosofia da arte dos primeiros românticos esta permanece na relação entre arte e vida e na valorização da vida pessoal do autor, na sua exposição como conteúdo temático dos quais são exemplos toda a body art, as impactantes fotografias de David Nebreda, a obra da inglesa Tracey Emin, também de Abramovich, de Elina Brotherus, ou do brasileiro Oiticica, de Lygia Clark, Lygia Pape, de Leonilson, de Nazareth Pacheco entre tantos, e de todas as práticas artísticas da estética relacional.

Sob esta perspectiva, ambas linhas se desenvolveram no modernismo concomitantemente num processo de retroalimentação, a partir da qual, uma linha atinge sua meta (seu fim como objeto [ente] que representa algo distinto do objeto) e a outra não, marcando uma o surgimento da arte contemporânea (pós-histórica) e a outra mantendo sua natureza alegórica ou representacional, que para Danto é sinal de seu anacronismo. Acreditamos, porém, que como ambas se desenvolveram numa relação simbiótica, a síntese a que chega uma produção de marcada natureza conceitual também está contaminada pela outra ainda que faça esta outra aparecer como um projeto esgotado, ultrapassado. 
É possível que Danto, não admitisse a existência entre duas vertentes artísticas porque isto representaria que o projeto romântico também tem eco na arte contemporânea e, portanto, tem relação com a diluição das fronteiras entre arte e filosofia. Tal fato seria contraditório dada a divergência entre Hegel e os românticos.

Hernandez Sánches( 2002) no capítulo Arte conceptual y mundo invertido analisa a relação entre a filosofia de Hegel e a arte conceitual demonstrando através de vários exemplos que nesta última parte da produção reivindica e coqueteia com o irracional e o sensível (p.185).

\begin{abstract}
$\mathrm{Y}$, sin embargo, estas ideas, que culminan en todo tipo de mentalismo y solipsismos, remiten únicamente a esas posturas iniciales del arte de concepto, las versiones más analíticas. Pero no todo el arte de concepto se reduce a este modelo lingüístico y tautológico de los planteamientos iniciales, planteamientos, y hay que insistir en ello, que se encuentran mucho más en las propuestas teóricas que en las prácticas artísticas de los mismos autores. Como lo ha visto claramente Simón Marchán, habría una segunda versión del 'concepto', donde la prioridad la tiene el proyecto, los juegos de asociaciones y comparaciones entre el concepto y la percepción, y que, por tanto, no elimina la materialización del objeto artístico. (Hernandez Sánchez, 2002, p.186 - 187). ${ }^{8}$
\end{abstract}

Além do eco na produção artística contemporânea, aceitar a proposição romântica de valorização da subjetividade como elemento que limita o projeto racional hegeliano implicaria ter que abrigar no seio das possibilidades teóricas de interpretações, diversas abordagens que ele não considera úteis para analisar a produção artística que demonstra a conclusão do projeto de autoconsciência da arte.

Esta não aceitação da filosofia romântica de Jena por parte de Danto auxilia a entender o porquê, no seu entendimento a arte moderna demonstra a insuficiência de uma interpretação da arte como expressão de subjetividades, da qual as leituras de Benedetto Croce são exemplo. Igualmente, auxilia a entender porque ficam também descredenciadas ao seu ver, as teorias estruturalistas, marxistas e psicanalíticas (Danto, 2014, p.90 a 95) pois, segundo Danto, estas enxergam nas diferenças estilísticas da arte a manifestação de visões ideológicas distintas de mundo uma vez que colocam a arte na passiva posição superestrutural, análise esta com a qual concordamos (Danto, 2014, p.52). E, naturalmente também ficam descredenciadas, em sua visão - mas aqui discordamos- as teorias fenomenológicas, hermenêuticas, e pós -estruturalistas- todas devedoras da filosofia romântica pelo caráter aberto (poderia se dizer subjetiva) de suas interpretações - ao passo que o autor americano defende uma interpretação que se aproxime ao máximo possível da interpretação (poderia se dizer concepção) do artista sobre sua própria obra (Danto, 2014, p.79).

É difícil saber se são mais de admirar os antigos adivinhadores por terem percebido uma estrutura exibida repetidamente em algumas das mais influentes ciências-humanas ou de suspeitar destes últimos empreendimentos hermenêuticos por encontrarem satisfação cognitiva em estruturas de uma era mais ignorante e

\footnotetext{
$8 \mathrm{E}$, no entanto, estas ideias, que terminam em todo o tipo de mentalismo e solipsismo, referem-se apenas às posições iniciais de arte conceitual, as versões mais analíticas. Mas nem toda arte conceitual se reduz a este modelo linguístico e tautológico das ideias iniciais, abordagens e devemos insistir, que se encontram muito mais nas propostas teóricas que nas práticas artísticas dos mesmos autores. Como viu claramente Simon Marchan, haveria uma segunda versão do "conceito", onde a prioridade a possui o projeto, os jogos de associações e comparações entre conceito e percepção, e, portanto, não elimina a materialização do objeto artístico. (Tradução nossa)
} 
crédula. [...] Mas hesito em oferecer uma interpretação profunda da interpretação profunda não só porque tenho algumas sérias reservas sobre um empreendimento não menos suspeito quando exercido sobre si mesmo em audesconstrução, mas também porque desejo mostrar como é fácil evitar o medonho círculo hermenêutico, ou seja, recusando-se a entrar nele, evitando totalmente a hermenêutica. (Danto, 2014, p.95).

Este artigo não tem por objetivo defender a tese dos primeiros românticos de resolução do problema ontológico do conhecimento frente a proposição hegeliana. Esta discussão, pertence ao âmbito estrito da filosofia. Tampouco sugerir uma onipresença das teses românticas na produção artística contemporânea ou desqualificar a tese de Danto. Ao propor uma problematização desta com a incorporação do eco das teses românticas na arte contemporânea se compreende melhor como esta divergência entre Hegel e os românticos se desdobra na filosofia da arte e nas repercussões que esta querela possa ter tido não apenas nas produções artísticas das décadas subsequentes mas também nas teorias interpretativas sobre a arte como a hermenêutica ou a fenomenologia (Heidegger, Gadamer, Váttimo, Pareyson e Merleau-Ponty).

Negar a pertinência de todas estas interpretações só é possível se tomarmos o modernismo como uma linha única que dá continuidade ao processo histórico que finaliza na autoconsciência da arte porque, segundo Danto, a arte só pode ser pensada em termos de um modelo progressivo se for entendida como representação e não como expressão. Isto é coerente se pensarmos na relação entre arte e história da arte, pois é a relação entre ambas que permite ver que a arte chega ao seu fim como representação. Mas a relação entre arte e filosofia é plural - e aqui é onde acreditamos que há necessidade de relativizar o argumento de Danto - e como a herança romântica, de fato, atravessou o Século XIX e o Século XX, seria precipitado negar valor as abordagens interpretativas que buscam compreender a relação entre arte $\mathrm{e}$ filosofia da arte do ponto de vista da subjetividade e expressividade pois sua utilidade ainda se faria valer e talvez, não apenas para as obras que preservam a diferença entre objeto de representação e objeto representado.

E se a filosofia da arte significar apenas a histórica relação da arte como representação mimética, uma análise que evidencie a liberação da arte desta filosofia deve considerar as teses dos primeiros românticos porque - foram estes, e não Hegelquem justamente propuseram a diluição destas fronteiras e a transformação da arte em filosofia e da filosofia em arte.

Nas palavras de Pedro Duarte, a partir da tese dos primeiros românticos:

Nas obras de arte em que reconhecemos pensamento e nos escritos filosóficos em que somos tomados pelo tom poético, não estariam momentos casuais e desvios desafortunados nos quais se confundiria o que é arte com o que é filosofia. Pelo contrário. Tais momentos tornariam patente o que fica latente em outros, a saber, que filosofia e poesia partilham o espaço da linguagem em que se inventam a sí mesmas. Portanto, jamais está definido de antemão, no sentido ontológico, onde fica uma e onde fica outra. (...) Embora existam exceções, filosofia e arte foram, de Platão a Hegel, mantidas pretensamente à distância uma de outra, ao contrário do que os românticos propunham para a modernidade (Duarte, 2011, p.154). 
Para finalizar - embora não entendamos assim - a tese de Danto pode sugerir que uma interpretação da obra de arte contemporânea herdeira da tradição artística que encontra seu fim, seja inadequada sempre que esta interpretação localize referências históricas ou genealógicas. No entanto, se arte é linguagem - e deve obrigatoriamente ser para que tenha atingido sua autoconsciência filosófica - somente pode ser aprendida e formulada pelo conhecimento e entendimento prévio de seus elementos constitutivos, os quais possuem uma historicidade para não dizer uma genealogia. A reflexão de Danto é poderosa tanto pela articulação que estabelece entre filosofia, arte e a História da arte (como disciplina) quanto pelas conclusões a que chega. No entanto, em nosso entendimento, ao desconsiderar a influência romântica nas proposições artísticas do Século XIX e primeira metade do XX acaba por desqualificar precipitadamente parte da produção da segunda metade do Século XX e a validez de algumas abordagens teóricas cujas utilizações seguem sendo recorrentes e úteis.

Por esta razão, nada mais justo que, como disse ao início, concluir reafirmando a citação de Berlin:

A visão de que há muitos valores e que eles são incompatíveis; toda a noção de pluralidade, de inesgotabilidade, da imperfeição de todas as respostas e arranjos humanos; a ideia de que nenhuma resposta que afirme ser verdadeira, seja na arte ou na vida, pode, em princípio, ser perfeita ou verdadeira - tudo isso devemos aos românticos (Berlin, 2015, p. 216).

\section{Referências}

BERLIN, Isaiah. As raízes do Romantismo. São Paulo: Três estrelas, 2015.

DANTO, Arthur. O descredenciamento filosófico da arte. Belo Horizonte: Autêntica, 2014. . Após o fim da arte. São Paulo: EDUSP, 2006.

DUARTE, Pedro. Estio do tempo. Rio de Janeiro: Zahar, 2011.

FRANCO JUNIOR, Hilário. A Eva barbada. São Paulo: Edusp, 1996.

GABRIEL, Markus \& ZIZEK, Slavoj. Mitologia, loucura e riso: a subjetividade no idealismo alemão. Rio de Janeiro: Civilização Brasileira, 2012.

HEGEL, G.W.F. Lecciones sobre la estética. Ed. Akal, Madrid, 1989

HERNANDEZ SANCHEZ, Domingo. La ironia estética. Ed. Universidad de Salamnca, Espanha, 2002. 
HERNANDEZ, Javier Dominguez, Religión del arte o comprensión del arte? La crítica de Hegel al Romanticismo. Estudios de Filosofía. Colombia: Instituto de Filosofía de la Universidad de Antioquia, 2003.

KRAUSS, Rosalind: La originalidad de la vanguardia y otros mitos modernos. Ed. Alianza, Madrid, 1996.

NEUMANN, Eckhard. Mitos de artista. Madrid: Tecnos, 1992.

NUNES LOPES, Daniel Rossi. Platão: a República, libro X. Campinas 2002. Dissertação de mestrado/UNICAMP.

PINHEIRO, Marcus Reis. A crítica aos poetas no livro X da República. Revista Calíope. N.16, Rio de Janeiro, UFRJ, 2007.

ROSENBLUM, Robert. La pintura moderna y la tradición del romanticismo nórdico de Friedrich a Rothko. Madrid: Alianza, 1993.

SCHLEGEL, Friedrich. Poesía y filosofia. Ed. Alianza Universidad, Madrid, 1994

VARES, Sidney. O problema da arte no pensamento de Platão. In: Viva Vox - DFL. Universidade Federal de Sergipe. Ano 3 - n.6 Jul. - Dez. 2010.

VILLELA-PETI, Maria da Penha. Platão e a poesia na República. Revista Kriterion, Faculdade de Filosofia da UFMG. Belo Horizonte, no 107, p.51-71, Junho 2003.

WARNKE, Martin. O artista da corte: os antecedentes dos artistas modernos. São Paulo: EDUSP, 2010.

Recebido em: 30/09/2015

Aprovado em: 05/02/2016 